\title{
Psychosis in nalidixic acid overdosage
}

\author{
Manel Fernando ${ }^{1}$, M A I Fonseka ${ }^{2}$, G L E C Mendis ${ }^{3}$, M L M Infaaq ${ }^{4}$
}

Sri Lanka Journal of Child Health, 2011; 40(3): 138-139

(Key words- Nalidixic acid; overdosage; psychosis)

DOI: $\underline{\text { http://dx.doi.org/10.4038/sljch.v40i3. } 3516}$

Nalidixic acid is the first antimicrobial in the Quinolone group and is still widely used in Sri Lanka for urinary tract infection (UTI) and dysentery. Taking into account the pharmacokinetics of the $\operatorname{drug}^{1,2}$, it is totally absorbed from the intestine very rapidly. It has an approximate plasma half life ( $1 / 2)$ of 6 hours and is readily eliminated by the kidney.

Adverse reactions of the drug ${ }^{1,2,3}$ are more commonly due to drug toxicity than to allergy. Drug toxicity manifests when the dose exceeds the therapeutic dose $(50-55 \quad \mathrm{mg} / \mathrm{kg} / \mathrm{day})$. Documented toxic effects include gastrointestinal symptoms, mild skin reactions, serious central nervous system (CNS) involvement and metabolic derangement (hyperglycaemia $^{4}$, lactic acidosis ${ }^{5,6,7}$ ). Rare but fatal haematological manifestations such as haemolytic anaemia ${ }^{8}$ and thrombocytopenia ${ }^{0}$ have also been noted on several occasions.

CNS toxicity predominantly includes convulsions and benign intracranial hypertension $(\mathrm{BIH})^{7,10.11}$, which present with headache, vomiting, visual disturbances (diplopia) and papilloedema beyond infancy. Other documented adverse effects are disturbances in sensorium, pyramidal and extrapyramidal signs with transitory psychotic syndrome. This psychotic syndrome has been reported in some international journals in adult patients but not in children. We are reporting a child who had abnormal behaviour following acute nalidixic acid overdosage.

\section{Case report}

A previously well eight year old girl $(24 \mathrm{~kg})$ was

${ }^{1}$ Consultant Paediatrician, ${ }^{2}$ Senior Registrar in Paediatrics, ${ }^{3}$ Senior House Officer in

Paediatrics, ${ }^{4}$ Registrar in Paediatrics, Colombo North Teaching Hospital, Ragama,

(Received on 2 November 2010: Accepted on 17 December 2010) admitted to ward 02 North Colombo Teaching Hospital Ragama with a history of sudden onset irritability and aggressive behaviour. She has been given medications for fever and dysuria at a local hospital. On questioning we found that she has been given $1 \mathrm{~g}$ of nalidixic acid $(42 \mathrm{mg} / \mathrm{kg} / \mathrm{dose})$ which was ingested three hours before the onset of this aggressive behaviour. It is three times the therapeutic dose (12.5mg/kg/dose).

While observing the child we found that her symptoms were biphasic. She had short intervals of staring without verbal communication followed by periods of aggressive behavior. During the aggressive phase she was excited and tried to run away, bite the mother and wiped her body with her hands as if she felt some abnormal sensations. There were no convulsions.

On examination, she was found to be irritable, aggressive and febrile. Her respiratory rate was 20 cycles per minute and there was no respiratory distress. She was haemodynamically stable without any bleeding manifestations. There were no gastrointestinal symptoms. CNS examination revealed a conscious, confused child with normal cranial nerves, motor and cerebellar systems with equal pupils reacting to light with normal optic fundi.

Our provisional diagnosis at this stage was psychosis due to acute overdosage of nalidixic acid. Active interventions were not done based on the advice given by the poison centre, National Hospital Sri Lanka, Colombo. Basic investigations like full blood count, random blood sugar, serum electrolytes were within normal limits. A blood gas analysis was not done as there was no clinical evidence of acidosis. These symptoms persisted for two hours and gradually settled and the child showed normal behaviour after about six hours from the initial presentation. 


\section{Discussion}

The history of exposure to a toxic dose of nalidixic acid which induced a psychotic state lasting for two hours with gradual recovery six hours after the exposure (which is the $t \frac{1}{2}$ of nalidixic acid) favours the clinical diagnosis of nalidixic acid related transitory psychotic syndrome. We were unable to do drug levels as it is not available in Sri Lanka.

Quinolones inhibit GABA receptors ${ }^{5}$ in human CNS by precipitating convulsions and altered behaviour. Similarly nalidixic acid interfere with lactic acid metabolism ${ }^{6}$ causing high lactic acid levels giving rise to metabolic acidosis and altered sensorium. Although our child showed altered behaviour, she did not have convulsions, signs of BIH or evidence of acidosis.

The head of the particular local hospital was informed to educate the relevant person who has irrationally given the overdose of nalidixic acid. We have informed this case to the drug evaluation sub committee in pharmacology department faculty of medicine, Colombo.

\section{Conclusion}

Toxic effects related to an inappropriately high dose of nalidixic acid have been reported in several occasions in Sri Lanka, Hence it is essential to update the knowledge of relevant authorities (Medical officers and pharmacists) about commonly used drugs and dosages through awareness programmes.

\section{References}

1. Dukes MNG (Editor), Malinverni R, Hoigne R, Sonntage R. Meyler's side effects of drugs (an encyclopedia of adverse reactions and interactions). $13^{\text {th }}$ ed. Elsevier science BV 1996; 25.1:858-59.

2. Bennett PN, Brown MJ. Clinical pharmacology. $10^{\text {th }}$ ed. USA; Elsevier: 2007. p. 204-5.
3. British National Formula for children. 2007.

4. Fraser AG, Harrower AD, Convulsion and hyperglycaemia associated with Nalidixic acid. British Medical Journal 1977; 2: 1518. http://dx.doi.org/10.1136/bmj.2.6101.1518

5. Suganthi AR, Raman AS, Pandit N, Yeshwanth M. Severe metabolic acidosis in nalidixic acid overdosage. Indian Paediatrics. 1993; 30:1025-6.

6. Eizadi-mood N, Gheshlaghi F. Nalidixic acid overdose and metabolic acidosis. CJEM 2006; 8(2):78.

7. Punchihewa PMG, Gunawardana MKS. Metabolic acidosis and benign intracranial hypertension in infants. Sri Lanka Journal of Child Health 2003; 32:20-2.

8. Tafani O, Mazzoli M, Landini G, Alterini B. fatal acute haemolytic anaemia caused by nalidixic acid. British Medical Journal 1982: 936.

9. Meyboom RH. Thrombocytopenia induced by Nalidixic acid. British Medical Journal 1984; 289: 962.

http://dx.doi.org/10.1136/bmj.289.6450.962-a

10. Boreus LO, Sundstrom B. Intracranial hypertension in a child during treatment with Nalidixc acid. British Medical Journal. 1967; 2: 744-5.

http://dx.doi.org/10.1136/bmj.2.5554.744

11. Lucas GN. Benign intracranial hypertension in infancy (the bulging fontanel syndrome). Ceylon Journal of Child Health. 1986; 15: 25-7. 